\title{
Association between serum levels of soluble receptor for advanced glycation end products and circulating advanced glycation end products in type 2 diabetes
}

\author{
K. C. B. Tan • S. W. M. Shiu • W. S. Chow $\cdot$ L. Leng • \\ R. Bucala $\cdot$ D. J. Betteridge
}

Received: 19 May 2006 / Accepted: 6 July 2006 / Published online: 13 September 2006

(C) Springer-Verlag 2006

\begin{abstract}
Aims/hypothesis Activation of the receptor for advanced glycation end products (RAGE, also known as AGEspecific receptor [AGER]) has been implicated in the development of diabetic vascular complications. Blockade of RAGE using a soluble form of the receptor (sRAGE) suppressed vascular hyperpermeability and atherosclerosis in animal models. Since little is known about the regulation of endogenous sRAGE levels, we determined whether serum sRAGE is influenced by circulating AGEs and the severity of nephropathy in type 2 diabetic patients.

Materials and methods We recruited 150 healthy control and 318 diabetic subjects. Diabetic subjects were subdivided into those with proteinuria, microalbuminuria or normoalbuminuria. Serum sRAGE was assayed by ELISA and serum AGEs by competitive ELISA using a polyclonal rabbit antiserum raised against AGE-RNase.

Results Diabetic subjects had higher sRAGE (1,029.5 $\mathrm{pg} / \mathrm{ml}$ [766.1-1,423.0] interquartile range vs 1,002.6

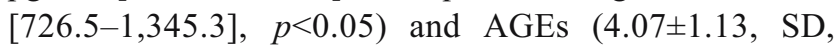
unit $/ \mathrm{ml}$ vs $3.39 \pm 1.05, p<0.01)$ than controls. Proteinuric
\end{abstract}

K. C. B. Tan $(\bowtie) \cdot$ S. W. M. Shiu $\cdot$ W. S. Chow

Department of Medicine, University of Hong Kong,

Queen Mary Hospital,

Pokfulam Road, Hong Kong SAR,

People's Republic of China

e-mail: kcbtan@hkucc.hku.hk

L. Leng $\cdot$ R. Bucala

Departments of Medicine and Pathology,

Yale University School of Medicine,

New Haven, CT, USA

\section{J. Betteridge}

Department of Medicine,

Royal Free and University College London Medical School, London, UK subjects had the highest sRAGE levels and there was a significant trend between the severity of nephropathy and sRAGE $(p=0.01)$. In diabetic subjects, serum $\log (\mathrm{sRAGE})$ correlated with AGEs $(r=0.27, p<0.001), \log ($ plasma creatinine) $(r=0.31, p<0.001), \log ($ urine AER) $(r=0.24$, $p<0.01)$ and $\log$ (triglycerides) $(r=0.15, p<0.01)$. On stepwise linear regression analysis, AGEs and creatinine levels were the main independent determinants of sRAGE concentration.

Conclusions/interpretation Serum sRAGE levels and circulating AGEs are associated with the severity of nephropathy in type 2 diabetic patients. Prospective studies are required to determine whether endogenous sRAGE potentially influences the development of diabetic vascular complications.

Keywords Advanced glycation end products .

Nephropathy · Soluble receptor for advanced glycation end product - Type 2 diabetes mellitus
Abbreviations
ACEI ACE inhibitor
AIIA angiotensin II receptor antagonist
esRAGE endogenous secretory receptor for advanced glycation end products
CRP C-reactive protein
RAGE receptor for advanced glycation end products
sRAGE soluble receptor for advanced glycation end products

\section{Introduction}

Hyperglycaemia leads to non-enzymatic glycation of intracellular and extracellular proteins with the formation 
of AGEs, the binding of which to their cellular receptors plays an important role in the development of diabetic vascular complications [1]. The best-characterised receptor for AGEs is the receptor for AGEs (RAGE, also known as AGE-specific receptor [AGER]). RAGE belongs to the immunoglobulin superfamily of cell-surface molecules and is composed of an extracellular region containing one V-type and two C-type immunoglobulin domains, a hydrophobic transmembrane domain and a highly charged short cytosolic tail, which is essential for postRAGE signalling [2]. The role of RAGE in diabetic vasculopathy has been investigated in animal and human studies. The engagement of RAGE by AGEs activates key cell signalling pathways such as mitogen-activated protein kinases and nuclear factor- $\mathrm{kB}$, resulting in a perturbation of a variety of homeostatic functions of the vasculature and induction of cellular oxidant stress [3,4]. Transgenic mice over-expression of RAGE exacerbates diabetic nephropathy and retinopathy, whereas RAGEnull mice fail to develop signs of nephropathy [5-7]. Blockade of RAGE activation using a recombinant soluble form of RAGE or function-blocking antibodies has been shown to suppress vascular hyperpermeability, the development of atherosclerotic lesions and to enhance wound healing in diabetic rodents [8-10].

Recent studies have identified novel gene splice variants of the human receptor RAGE [11-13]. Three major $R A G E$ mRNA variants have been identified. One of these encodes the full-length RAGE, which has full signalling and AGEbinding potential. Another, encodes N-truncated RAGE, a membrane-bound isoform that contains no AGE-binding domain. And the third encodes C-truncated soluble RAGE (sRAGE), which has AGE-binding properties in the absence of a signalling cascade. Experimental studies have suggested that sRAGE can act as a decoy for RAGE ligands and thus have cytoprotective properties against AGE actions [8-10]. Studies investigating total circulating level of sRAGE have shown that sRAGE levels were reduced in non-diabetic subjects with coronary heart disease and in those with essential hypertension [14, 15], but were increased in patients with impaired renal function, especially those with end-stage renal disease [16]. In patients with type 1 diabetes mellitus, Challier et al. reported that serum sRAGE concentration was significantly increased compared to non-diabetic controls and that patients with retinopathy had the highest sRAGE level [17]. When an assay measuring endogenous secretory RAGE (esRAGE) was used, circulating esRAGE levels were reduced in type 1 diabetic patients compared to nondiabetic controls. There was an inverse association between esRAGE and carotid intima-media thickness and patients with retinopathy had lower esRAGE than those without retinopathy [18]. Another study reported that plasma
esRAGE was significantly lower in type 2 diabetic subjects than non-diabetic controls [19] and was also inversely correlated with $\mathrm{HbA}_{1 \mathrm{c}}[19,20]$. Since relatively little is known about factors influencing total circulating sRAGE levels in diabetes, we examined the relationship between sRAGE and serum AGEs concentration in type 2 diabetic patients with and without nephropathy.

\section{Subjects and methods}

Type 2 diabetic patients were recruited from the diabetes clinics at Queen Mary Hospital, Hong Kong. Patients on insulin therapy were eligible if they had been previously managed with diet and an oral agent at some point and had no known history of diabetic ketoacidosis. Healthy control subjects were recruited from the community. Diabetic patients were invited to participate when they attended their annual screening visit for diabetic complications and were divided, according to their urinary AER, into three groups: those with normoalbuminuria $(<30 \mathrm{mg} /$ day $)$, those with microalbuminuria $(30-300 \mathrm{mg} /$ day $)$, and those with proteinuria $(>300 \mathrm{mg} /$ day). Power calculation showed that a sample size of 96 subjects in each group was required to detect an effect size of 0.35 with $80 \%$ power at a $5 \%$ alpha level. Consecutive patients were recruited until each group had a minimum of 100 subjects. The overall participation rate was approximately $80 \%$. Macrovascular disease was defined as evidence of ischaemic heart disease (according to clinical history and Minnesota coding of ECG), stroke, transient ischaemic attack or peripheral vascular disease. Diagnosis of retinopathy was based on fundoscopic finding by ophthalmoscopy (with pupils dilated to $>3 \mathrm{~mm}$ in diameter). The 150 healthy controls were recruited from the community by advertisement, with exclusion of subjects who had a history of any chronic illness and/or were receiving regular medications. Subjects with a fasting plasma glucose $\geq 6.1 \mathrm{mmol} / 1$ were also excluded from the control group. In all subjects, fasting blood samples were taken for the measurement of glucose, lipids, $\mathrm{HbA}_{1 \mathrm{c}}$, C-reactive protein (CRP) and serum AGEs and sRAGE. The study was approved by the Ethics Committee of the University of Hong Kong and informed consent was obtained from all subjects.

Serum AGEs were measured by means of a competitive ELISA developed in-house and using a well-characterised polyclonal rabbit antiserum raised against AGE-RNase as previously described [21]. In brief, 96-well plates were coated with $50 \mu \mathrm{l} /$ well of AGE-RNase $(3.75 \mu \mathrm{g} / \mathrm{ml})$ and $50 \mu \mathrm{l}$ of serum (1:4 dilution) added, followed by $50 \mu \mathrm{l}$ of 1:500 diluted anti-AGE antibody. Alkaline phosphateconjugated anti-rabbit $\operatorname{IgG}(1: 2,000)$ in dilution buffer was then added to each well and incubated for $1 \mathrm{~h}$ at $37^{\circ} \mathrm{C}$. 
After washing, colour was developed by adding $100 \mu \mathrm{l}$ p-nitrophenylphosphate substrate (Sigma, St Louis, MO, USA). Optical density (OD) at $405 \mathrm{~nm}$ was determined by an ELISA reader. Results were calculated as: 1-([experimental OD-background OD]/[total OD-background OD]). A 50\% competition was defined as $1 \mathrm{U}$ of AGEs. The intra- and interassay coefficients of variation were 2.5 and $7.4 \%$, respectively.

Serum sRAGE levels were determined using ELISA (Quantikine; R \& D systems, Minneapolis, MN, USA) according to the manufacturer's protocol. Briefly, a monoclonal antibody raised against the N-terminal extracellular domain of human RAGE consisting of amino acids Gln 24 through Ala 344 was used to capture sRAGE from serum. Captured sRAGE was detected with a polyclonal antihuman sRAGE antibody. After washing, plates were incubated with streptavidin horseradish peroxidase, developed with appropriate substrate and OD450 was determined using an ELISA plate reader. Samples were assayed in duplicate and in random order. Mean minimal detectable dose of RAGE was $4.12 \mathrm{pg} / \mathrm{ml}$. The intra- and interassay coefficients of variation were 1.9 and $5.5 \%$, respectively.

Plasma high-sensitivity CRP was measured by a particle-enhanced immunoturbidimetric assay (Roche Diagnostics, Mannheim, Germany) using anti-CRP mouse monoclonal antibodies coupled to latex microparticles. Plasma total cholesterol and triglycerides were determined enzymatically on an analyser (Hitachi 912; Roche Diagnostics). HDL-cholesterol was measured using a homogenous method with polyethylene glycol-modified enzymes and alpha-cyclodextrin. LDL-cholesterol was calculated by the Friedewald equation. $\mathrm{HbA}_{1 \mathrm{c}}$ was measured in whole blood using ion-exchange high-performance liquid chromatography with the Bio-Rad Variant Haemoglobin Testing System (Bio-Rad Laboratories, Hercules, CA, USA). Urinary AER was determined from the mean of two consecutive 12-h overnight urine collections. Urine albumin was measured by rate nephelometry using the Beckman Array 360 Analyser (Beckman-Coulter, Fullerton, CA, USA). Creatinine clearance was calculated using the Cockcroft-Gault formula [22].

Results are expressed as mean and standard deviation, or as median and interquartile range if the distribution of the data were found to be skewed. Data that were not normally distributed were logarithmically transformed before analyses were made. The chi-squared test was used to compare differences in proportions between groups. Analysis of variance was used to compare continuous variables for multiple groups followed by post hoc multiple comparisons using Dunnett $t$ tests with the non-diabetic control as the reference group. Pearson's correlations were used to test the relationship between variables. Polynomial contrast test was used to test for a trend between serum sRAGE and the severity of nephropathy. Multiple stepwise linear regression analysis was used to assess the relationships between sRAGE and various variables simultaneously.

\section{Results}

The clinical characteristics of the control and diabetic subjects are shown in Table 1. As expected, the proteinuric diabetic patients had more complications, higher blood pressure and a greater proportion of them were receiving insulin therapy, ACE inhibitors (ACEI) or an angiotensin II receptor antagonist (AIIA). There were, however, no significant differences in the duration of diabetes (Table 1) and glycaemic control amongst the three groups of diabetic patients on post hoc analysis (Table 2). When all type 2 diabetic subjects were analysed together and compared with control subjects, both serum AGEs $(4.07 \pm 1.13 \mathrm{U} / \mathrm{ml}$ vs $3.39 \pm 1.05$, respectively, $p<0.01)$ and sRAGE $(1,029.5 \mathrm{pg} / \mathrm{ml}$ [766.1-1,423.0] vs 1,002.6 [726.5-1,345.3], respectively, $p<0.05)$ were significantly increased in the diabetic patients. Results of serum AGEs and sRAGE of the diabetic patients according to nephropathy status are shown in Table 2. Serum AGEs were significantly higher in all three groups of diabetic patients than in control subjects, whereas serum sRAGE was significantly increased in the proteinuric patients. Repeating the analyses after adjusting for age, sex, BMI and smoking did not change our results. Since previous studies have suggested associations between sRAGE and coronary atherosclerosis, we analysed the data after excluding those subjects with macrovascular disease. Serum sRAGE levels remained significantly higher in patients with proteinuria $(p=0.02)$. Polynomial contrast test showed that there was a significant trend between the severity of nephropathy and serum sRAGE in patients with diabetes $(p=0.01)$. In view of the potential association between serum sRAGE and retinopathy, analysis was also performed after excluding subjects with both macrovascular disease and retinopathy. Proteinuric patients still had the highest levels of sRAGE compared to the other groups and the trend between the severity of nephropathy and serum sRAGE persisted.

In the whole group of diabetic patients, $\log$ (sRAGE) correlated significantly with AGEs (Fig. 1) and with log (creatinine) (Fig. 2). Associations were also seen with creatinine clearance $(r=-0.30, p<0.001), \log$ (urine AER) $(r=0.24, p<0.01), \log$ (triglycerides) $(r=0.15, p<0.01)$ and age $(r=0.13, p=0.03)$. There was a trend towards a weak correlation with $\mathrm{HbA}_{1 \mathrm{c}}(r=0.10, p=0.07)$, with no significant correlation being found with $\log (\mathrm{CRP})$. To determine whether an association between serum AGEs and sRAGE persisted in the absence of nephropathy, analysis was repeated separately in diabetic subjects with normoalbu- 
Table 1 Clinical characteristics of diabetic patients and control subjects

\begin{tabular}{|c|c|c|c|c|c|}
\hline & \multirow[t]{2}{*}{ Control } & \multicolumn{3}{|l|}{ Diabetic patients } & \multirow{2}{*}{$\begin{array}{l}\text { ANOVA } \\
p \text { value }\end{array}$} \\
\hline & & Normoalbuminuria & Microalbuminuria & Proteinuria & \\
\hline Number of subjects & 150 & 110 & 108 & 100 & - \\
\hline $\mathrm{M} / \mathrm{F}(\%)$ & $50 / 50$ & $48 / 52$ & $53 / 47$ & $66 / 34$ & $0.01^{\mathrm{a}}$ \\
\hline Age (years) & $51.0 \pm 5.8$ & $51.4 \pm 6.9$ & $53.3 \pm 8.9$ & $54.2 \pm 9.9 * *$ & 0.005 \\
\hline BMI $\left(\mathrm{kg} / \mathrm{m}^{2}\right)$ & $24.6 \pm 3.3$ & $25.3 \pm 3.9$ & $26.4 \pm 3.9 * * *$ & $26.7 \pm 4.5 * * *$ & $<0.001$ \\
\hline Smokers $(\%)$ & 18 & 12 & 12 & 16 & NS \\
\hline Duration of diabetes (years) & - & $12.1 \pm 6.4$ & $10.8 \pm 7.6$ & $10.4 \pm 5.8$ & NS \\
\hline Cardiovascular disease $(\%)$ & - & 2.7 & 3.7 & 13.0 & $0.01^{\mathrm{a}}$ \\
\hline Retinopathy $(\%)$ & - & 26.4 & 30.6 & 66.0 & $<0.001^{\mathrm{a}}$ \\
\hline Insulin $(\%)$ & - & 29.1 & 28.7 & 50.0 & $<0.001^{\mathrm{a}}$ \\
\hline ACEI or AIIA (\%) & - & 44.5 & 60.2 & 83.0 & $<0.001^{\mathrm{a}}$ \\
\hline Systolic BP (mmHg) & $116.3 \pm 16.5$ & $122.2 \pm 15.0 *$ & $128.5 \pm 13.6^{* * *}$ & $139.4 \pm 28.5^{* * *}$ & $<0.001$ \\
\hline Diastolic BP (mmHg) & $74.5 \pm 9.3$ & $75.3 \pm 8.5$ & $76.7 \pm 8.8$ & $79.0 \pm 10.0 * * *$ & 0.001 \\
\hline
\end{tabular}

Values are mean \pm SD. Post hoc analysis

${ }^{*} p<0.05$ vs control subjects

$* * p<0.01$ vs control subjects

$* * * p<0.001$ vs control subjects

${ }^{a} p$ value of chi-squared test

minuria and in those with microalbuminuria or proteinuria. Serum AGEs correlated with $\log (\mathrm{sRAGE})$ in diabetic subjects with microalbuminuria or proteinuria $(r=0.26$, $p<0.01)$ and also in diabetic subjects with normoalbuminuria ( $r=0.21, p=0.03$ ), suggesting that the association between AGEs and sRAGE was not solely due to changes

Table 2 Glycaemic control, fasting lipids, serum AGEs and sRAGE in diabetic patients and control subjects

\begin{tabular}{|c|c|c|c|c|c|}
\hline & \multirow[t]{2}{*}{ Control } & \multicolumn{3}{|l|}{ Diabetic patients } & \multirow{2}{*}{$\begin{array}{l}\text { ANOVA } \\
p \text { value }\end{array}$} \\
\hline & & Normoalbuminuria & Microalbuminuria & Proteinuria & \\
\hline $\begin{array}{l}\text { Fasting glucose } \\
(\mathrm{mmol} / \mathrm{l})\end{array}$ & $4.8 \pm 0.5$ & $9.0 \pm 2.6^{* * *}$ & $8.5 \pm 2.3 * * *$ & $8.9 \pm 3.2 * * *$ & $<0.001$ \\
\hline $\mathrm{HbA}_{1 \mathrm{c}}(\%)$ & $5.6 \pm 0.5$ & $8.6 \pm 1.6^{* * *}$ & $8.3 \pm 1.2 * * *$ & $8.6 \pm 1.8 * * *$ & $<0.001$ \\
\hline $\begin{array}{l}\text { Total cholesterol } \\
(\mathrm{mmol} / \mathrm{l})\end{array}$ & $5.2 \pm 0.8$ & $4.8 \pm 0.9^{*}$ & $5.3 \pm 1.1$ & $5.2 \pm 1.0$ & 0.005 \\
\hline $\begin{array}{l}\text { Triglycerides } \\
(\mathrm{mmol} / \mathrm{l})\end{array}$ & $1.0(0.8-1.5)$ & $1.2(0.9-1.7)$ & $1.5(1.0-2.0)^{* *}$ & $1.5(1.2-2.3)^{* * *}$ & $<0.001$ \\
\hline LDL (mmol/1) & $3.1 \pm 0.7$ & $2.9 \pm 0.8$ & $3.2 \pm 0.9$ & $3.2 \pm 0.9$ & 0.012 \\
\hline HDL (mmol/l) & $1.5 \pm 0.4$ & $1.3 \pm 0.3 * * *$ & $1.2 \pm 0.4 * * *$ & $1.2 \pm 0.3 * * *$ & $<0.001$ \\
\hline Creatinine $(\mu \mathrm{mol} / 1)$ & $83.0(74.0-94.0)$ & $82.0(69.5-95.5)$ & $86.5(71.3-100.8)$ & $111.5(87.3-152.3)^{* * *}$ & $<0.001$ \\
\hline $\begin{array}{l}\text { Urinary albumin } \\
\text { excretion (mg/day) }\end{array}$ & - & $7(3-11)$ & $80(56-147)+$ & $\begin{array}{l}1,009 \\
(310-2,700) \dagger\end{array}$ & $<0.001$ \\
\hline $\begin{array}{l}\text { Creatinine clearance } \\
(\mathrm{ml} / \mathrm{min})\end{array}$ & - & $83.5 \pm 20.2$ & $81.6 \pm 26.2$ & $65.3 \pm 33.2 \ddagger$ & $<0.001$ \\
\hline AGEs (unit/ml) & $3.39 \pm 1.05$ & $3.57 \pm 0.95^{*}$ & $4.29 \pm 0.95^{* * *}$ & $4.33 \pm 1.17 * * *$ & $<0.001$ \\
\hline sRAGE (pg/ml) & $\begin{array}{l}1,002.6(726.5- \\
1,345.3)\end{array}$ & $\begin{array}{l}939.4(697.5- \\
1,293.4)\end{array}$ & $1,011.2(789.7-1,331.5)$ & $\begin{array}{l}1,201.7(846.6- \\
1,685.7)^{*}\end{array}$ & 0.01 \\
\hline CRP (mg/l) & $0.88(0.47-1.81)$ & $1.04(0.53-1.91)$ & $1.49(0.78-2.48)^{* *}$ & $1.89(0.80-4.19)^{* * *}$ & $<0.001$ \\
\hline
\end{tabular}

Values are mean $\pm \mathrm{SD}$ or median (interquartile range). Triglycerides, creatinine, urinary albumin excretion, sRAGE and C-reactive protein (CRP) were logarithmically transformed before analysis by ANOVA. Post hoc analysis

$* p<0.05$ vs control subjects

$* * p<0.01$ vs control subjects

$* * * p<0.001$ vs control subjects

$\$ p<0.01$ vs normoalbuminuric subjects 


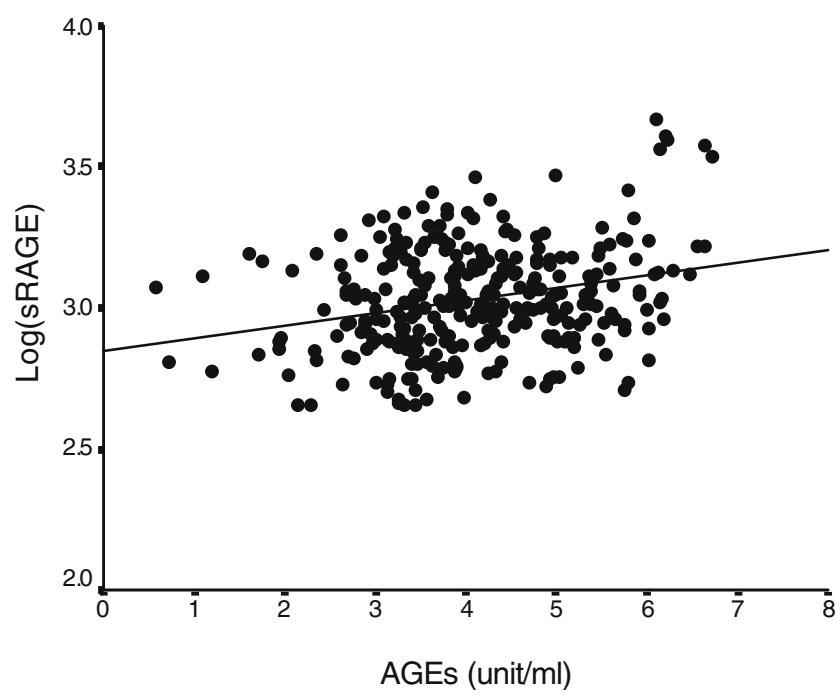

Fig. 1 Correlation between serum AGEs and $\log (\mathrm{sRAGE})$ in patients with diabetes. $r=0.27 ; p<0.001$

in renal function. In the control subjects, there was also a weak trend towards an association between $\log (\mathrm{sRAGE})$ and AGEs $(r=0.14, p=0.08)$ and age $(r=0.16, p=0.06)$.

Since a recent study has suggested that ACEI can increase the production and secretion of sRAGE into plasma [23], we investigated whether sRAGE levels were affected by ACEI/AIIA therapy. No significant differences in sRAGE were seen in subjects receiving ACEI/AIIA compared to those not $(1,030.5 \mathrm{pg} / \mathrm{ml}[755.7-1,491.0]$ vs $1,028.3$ [786.3-1,384.8], respectively). Analysis of the microalbuminuric and proteinuric group of subjects independently for the effect of ACEI/AIIA also did not reveal any significant differences. To investigate what the determinants of $\log$ (sRAGE) were in patients with diabetes, stepwise linear regression analysis was performed. Age, sex, BMI, smoking status, $\mathrm{HbA}_{1 \mathrm{c}}$, plasma lipids, log

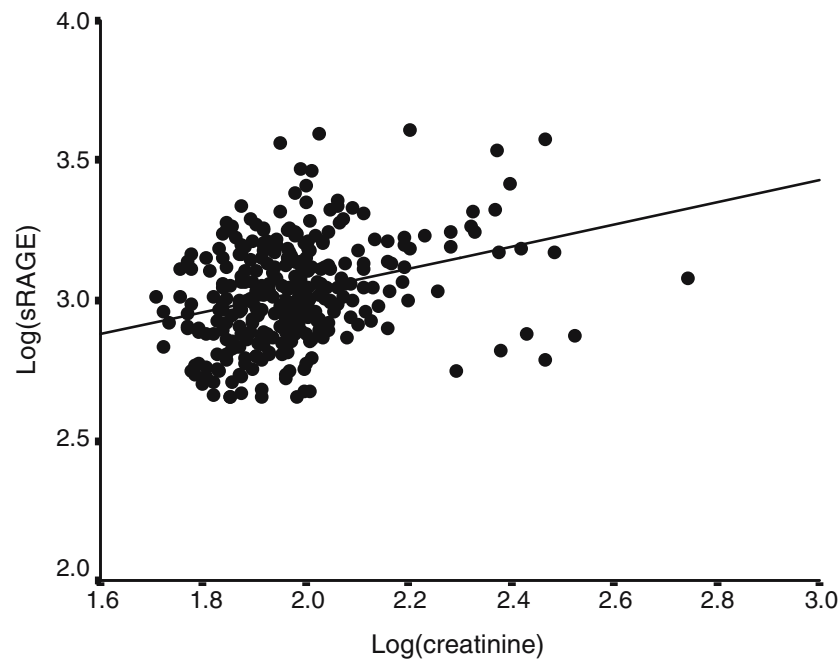

Fig. 2 Correlation between $\log$ (creatinine) and $\log ($ sRAGE $)$ in patients with diabetes. $r=0.31 ; p<0.001$ (creatinine), $\log$ (urinary albumin excretion), $\log (\mathrm{CRP})$ and treatment with ACEI/AIIA were entered into the model (creatinine clearance was not included in the model as it was closely correlated with plasma creatinine). The independent determinants of sRAGE were $\log$ (creatinine) and AGEs, accounting for 15 and $11 \%$ of the variation respectively $(p<0.001$ for the whole model).

\section{Discussion}

Data on serum total sRAGE levels in type 2 diabetes are scanty in the literature and to the best of our knowledge, this is the first study investigating the relationship between sRAGE and circulating AGEs, and severity of nephropathy in patients with type 2 diabetes mellitus. We found that serum sRAGE levels were highest in type 2 diabetic patients with proteinuria, with an association between sRAGE and the severity of nephropathy. Our results are in keeping with a recent brief report that plasma sRAGE was independently associated with urinary albumin excretion in Caucasian type 2 diabetic patients with albuminuria and normal glomerular filtration rate [24]. There was no non-diabetic control group in that study and the mean plasma sRAGE level was $1,191 \mathrm{pg} / \mathrm{ml}$ in the type 2 diabetic patients, which was similar to the concentration of sRAGE seen in our Chinese patients. Serum sRAGE has also been shown to be increased in type 1 diabetic patients with retinopathy [17]. In contrast, other studies that measured esRAGE found lower levels of esRAGE in diabetic patients $[18,19]$. Since we measured serum total sRAGE in our study, our results cannot be directly compared with studies in diabetic patients in whom plasma esRAGE levels were measured, as it has been suggested that esRAGE might constitute only part but not all of the human sRAGE in plasma [19]. The mean plasma esRAGE level is approximately one-fifth of the total sRAGE level in healthy individuals [19].

The mechanisms by which sRAGE might be generated in vivo and the question of what are the determinants of circulating sRAGE levels are poorly understood. The soluble form of RAGE measured in peripheral blood may be released by several cell types, such as endothelial cells and circulating leucocytes, and may result from cleavage of the full-length native membranous receptor by proteinases like matrix metalloproteinases and/or from the expression of an RAGE splice gene variant that encodes the amino-terminally truncated soluble form of the receptor [11-13, 25]. Several novel splice variants of $R A G E$, all encoding truncated sRAGE, have recently been identified. Schlueter et al. have shown that the relative expression ratios for the full length RAGE transcript to the sum of its 
splice-variants encoding truncated soluble variants varied strongly among tissues and concluded that the pre-mRNA of $R A G E$ must be subject to regulated alternative splicing activated by extracellular cues of yet unknown cellular signalling pathways [12]. As a result, it has been suggested that human sRAGE production might be regulated by alternative splicing as well as by release from the full-length RAGE receptor by proteinases [26].

We have shown for the first time a positive correlation between serum sRAGE and AGEs, which suggests that AGEs may be one of the factors influencing sRAGE levels. Although serum measurement of AGEs may not necessarily reflect cumulative tissue levels of AGEs, it has been suggested that serum levels correlate with AGEs levels in the vessel wall [27]. RAGE is normally expressed only at low levels by the endothelium, smooth muscle, mesangial and monocytes [28]. However, high levels of RAGE expression have been identified in the retina, mesangial and aortic vessels, concomitant with AGE accumulation, both in animal models and in human diabetic subjects. AGEs have been shown to co-localise with RAGE, and AGEs-rich vasculature exhibits enhanced RAGE immunoreactivity $[29,30]$. Hence, in states of increased AGEs, RAGE expression is increased, and AGEs can stimulate $R A G E$ through activation of nuclear factor- $\mathrm{kB}$ in human vascular endothelial cells [31]. The ability of AGEs to modulate RAGE expression is likely to contribute to the pathological state of chronic activation of full-length RAGE in diabetes. Hence, increased AGEs in our diabetic patients might lead to increased cell surface RAGE and through that to higher levels of sRAGE generated directly from this species. Whether AGEs can also directly influence sRAGE expression by alternative splicing is not known and warrants further investigation. There are data suggesting that the pattern of $R A G E$ expression can be modulated. Forbes et al. recently showed that inhibition of the reninangiotensin system by ACEI can increase the production and secretion of sRAGE into plasma [23]. Since a large number of our diabetic patients were on ACEI or AIIA, this might potentially influence sRAGE levels in our patients, although we did not find a significant difference in sRAGE levels between patients receiving and not receiving ACEI/AIIA.

In addition, we also found an association between sRAGE and plasma creatinine. Together with a recent study reporting an increase in sRAGE in patients with decreased renal function [16], our data would suggest that renal function is also an important determinant of sRAGE level. Although the removal of AGEs and their degradative products is known to depend on renal clearance [32], little is known about the route of degradation and clearance of sRAGE. The molecular weight of sRAGE is approximately $35 \mathrm{kDa}$. sRAGE can thus potentially be freely filtered in the kidney and elimination of sRAGE may depend on tubular function. Whether the increase in sRAGE is caused solely by decreased renal function or whether sRAGE is upregulated to protect against the toxic effects of AGEs in renal impairment remains to be determined.

Our study has a number of limitations. Since it was cross-sectional in nature, we were only able to demonstrate associations and not causal relationships. Prospective studies are required to further investigate the regulation of endogenous sRAGE and to determine whether sRAGE is simply a marker of diabetic vascular complications or whether it can potentially influence the development of complications. Comparison with non-diabetic subjects with proteinuria would be helpful to further clarify and delineate the respective roles of diabetes and renal disease in the changes of sRAGE. If sRAGE turns out to be not just a biomarker, but also plays a role in the endogenous defence of tissue to AGEs, measurement of serum sRAGE could be used to monitor diabetic vascular disease as well as to evaluate the effect of potential intervention with a view to modulating sRAGE.

Another limitation of our study is that we used a polyclonal antibody to measure AGEs. However, AGEs are a heterogeneous group of compounds and the dominant AGE epitope for binding to RAGE is $N^{\varepsilon}$-(carboxymethyl) lysine. Measuring serum AGEs with a polycloncal antibody will detect most of the circulating AGEs and indeed the polyclonal anti-AGEs antibody raised against AGE-RNase has been shown to recognise $N^{\varepsilon}$-(carboxymethyl)lysine, as well as other AGE epitopes including non-fluorescent crosslink arginine-lysine imidazole [33, 34]. Since we also measured sRAGE by using antibodies generated generically to RAGE, we were unable to distinguish whether the species detected by this assay represented sRAGE cleaved or released from full-length endogenous receptor on the cell surface and/or novel splice variants of $R A G E$. For the same reason, we were also unable to delineate the specific cellular source(s) of sRAGE. The usefulness of measuring total sRAGE compared to esRAGE needs to be investigated.

In conclusion, there is an association between serum sRAGE levels and circulating AGEs, and the severity of nephropathy in patients with type 2 diabetes. The question of whether endogenous sRAGE influences the development of diabetic vascular complications warrants further investigation.

Acknowledgements This study was supported by funding from the Hong Kong Research Grants Council (HKU7350/02), and the NIH (to R. Bucala and L. Leng). 


\section{References}

1. Singh R, Barden A, Mori T, Beilin L (2001) Advanced glycation end-products: a review. Diabetologia 44:129-146

2. Bucciarelli LG, Wendt T, Rong L et al (2002) RAGE is a multiligand receptor of the immunoglobulin superfamily: implications for homeostasis and chronic disease. Cell Mol Life Sci 59:1117-1128

3. Schmidt AM, Yan SD, Wautier JL, Stern D (1999) Activation of receptor for advanced glycation end products: a mechanism for chronic vascular dysfunction in diabetic vasculopathy and atherosclerosis. Circ Res 84:489-497

4. Bierhaus A, Humpert PM, Morcos M et al (2005) Understanding RAGE, the receptor for advanced glycation end products. J Mol Med 83:876-886

5. Yamamoto Y, Yamagishi S, Yonekura H et al (2000) Roles of the AGE-RAGE system in vascular injury in diabetes. Ann N Y Acad Sci 902:163-170

6. Yamamoto Y, Kato I, Doi T et al (2001) Development and prevention of advanced diabetic nephropathy in RAGE-overexpressing mice. J Clin Invest 108:261-268

7. Wendt TM, Tanji N, Guo J et al (2003) RAGE drives the development of glomerulosclerosis and implicates podocyte activation in the pathogenesis of diabetic nephropathy. Am J Pathol 162:1123-1137

8. Wautier JL, Zoukourian C, Chappey O et al (1996) Receptormediated endothelial cell dysfunction in diabetic vasculopathy. Soluble receptor for advanced glycation end products blocks hyperpermeability in diabetic rats. J Clin Invest 97:238-243

9. Park L, Raman KG, Lee KJ et al (1998) Suppression of accelerated diabetic atherosclerosis by the soluble receptor for advanced glycation endproducts. Nat Med 4:1025-1031

10. Goova MT, Li J, Kislinger T et al (2001) Blockade of receptor for advanced glycation end-products restores effective wound healing in diabetic mice. Am J Pathol 159:513-525

11. Yonekura H, Yamamoto Y, Sakurai S et al (2003) Novel splice variants of the receptor for advanced glycation end-products expressed in human vascular endothelial cells and pericytes, and their putative roles in diabetes-induced vascular injury. Biochem $\mathrm{J}$ 370:1097-1109

12. Schlueter C, Hauke S, Flohr AM, Rogalla P, Bullerdiek J (2003) Tissue-specific expression patterns of the RAGE receptor and its soluble forms - a result of regulated alternative splicing? Biochim Biophys Acta 1630:1-6

13. Park IH, Yeon SI, Youn JH et al (2004) Expression of a novel secreted splice variant of the receptor for advanced glycation end products (RAGE) in human brain astrocytes and peripheral blood mononuclear cells. Mol Immunol 40:1203-1211

14. Falcone C, Emanuele E, D'Angelo A et al (2005) Plasma levels of soluble receptor for advanced glycation end products and coronary artery disease in nondiabetic men. Arterioscler Thromb Vasc Biol 25:1032-1037

15. Geroldi D, Falcone C, Emanuele E et al (2005) Decreased plasma levels of soluble receptor for advanced glycation end-products in patients with essential hypertension. J Hypertens 23:1725-1729

16. Kalousova M, Hodkova M, Kazderova M et al (2006) Soluble receptor for advanced glycation end products in patients with decreased renal function. Am J Kidney Dis 47:406-411

17. Challier $\mathrm{M}$, Jacqueminet $\mathrm{S}$, Benabdesselam $\mathrm{O}$, Grimaldi $\mathrm{A}$, Beaudeux JL (2005) Increased serum concentrations of soluble receptor for advanced glycation endproducts in patients with type 1 diabetes. Clin Chem 51:1749-1750
18. Katakami N, Matsuhisa M, Kaneto $H$ et al (2005) Decreased endogenous secretory advanced glycation end product receptor in type 1 diabetic patients: its possible association with diabetic vascular complications. Diabetes Care 28:2716-2721

19. Koyama H, Shoji T, Yokoyama H et al (2005) Plasma level of endogenous secretory RAGE is associated with components of the metabolic syndrome and atherosclerosis. Arterioscler Thromb Vasc Biol 25:2587-2593

20. Katakami N, Matsuhisa M, Kaneto H, Yamasaki Y (2006) Endogenous secretory receptor for advanced glycation end products are inversely associated with $\mathrm{HbA} 1 \mathrm{c}$ in type 2 diabetic patients. Diabetes Care 29:469

21. Tan KCB, WS Chow, VHG Ai, C Metz, R Bucala, KSL Lam (2002) Advanced glycation end products and endothelial dysfunction in type 2 diabetes mellitus. Diabetes Care 25:1055-1059

22. Cockcroft DW, Gault MH (1976) Prediction of creatinine clearance from serum creatinine. Nephron 16:31-41

23. Forbes JM, Thorpe SR, Thallas-Bonke V et al (2005) Modulation of soluble receptor for advanced glycation end products by angiotensin-converting enzyme-1 inhibition in diabetic nephropathy. J Am Soc Nephrol 16:2363-2372

24. Humpert PM, Kopf S, Djuric Z et al (2006) Plasma sRAGE is independently associated with urinary albumin excretion in type 2 diabetes. Diabetes Care 29:1111-1113

25. Hanford LE, Enghild JJ, Valnickova Z et al (2004) Purification and characterization of mouse soluble receptor for advanced glycation end products (sRAGE). J Biol Chem 279:50019-50024

26. Hudson BI, Harja E, Moser B, Schmidt AM (2005) Soluble levels of receptor for advanced glycation endproducts (sRAGE) and coronary artery disease: the next C-reactive protein? Arterioscler Thromb Vasc Biol 25:879-882

27. Stitt AW, He C, Friedman S et al (1997) Elevated AGE-modified apoB in sera of euglycemic, normolipidemic patients with atherosclerosis: relationship to tissue AGEs. Mol Med 3:617-627

28. Brett J, Schmidt AM, Yan SD et al (1993) Survey of the distribution of a newly characterized receptor for advanced glycation end products in tissues. Am J Pathol 143:1699-1712

29. Ritthaler U, Deng Y, Zhang Y et al (1995) Expression of receptors for advanced glycation end products in peripheral occlusive vascular disease. Am J Pathol 146:688-694

30. Soulis T, Thallas V, Youssef S et al (1997) Advanced glycation end products and their receptors co-localise in rat organs susceptible to diabetic microvascular injury. Diabetologia 40:619-628

31. Tanaka N, Yonekura H, Yamagishi S, Fujimori H, Yamamoto Y, Yamamoto H (2000) The receptor for advanced glycation end products is induced by the glycation products themselves and tumor necrosis factor-alpha through nuclear factor-kappa B, and by 17 beta-estradiol through $\mathrm{Sp}-1$ in human vascular endothelial cells. J Biol Chem 275:25781-25790

32. Dolhofer-Bliesener R, Lechner B, Gerbitz KD (1996) Possible significance of advanced glycation end products in serum in endstage renal disease and in late complications of diabetes. Eur J Clin Chem Clin Biochem 34:355-36

33. Berg TJ, Clausen JT, Torjesen PA, Dahl-Jorgensen K, Bangstad HJ, Hanssen KF (1998) The advanced glycation end product $\mathrm{N}$-epsilon-(carboxymethyl)lysine is increased in serum from children and adolescents with type 1 diabetes. Diabetes Care 21:1997-2002

34. Al-Abed Y, Bucala R (2000) Structure of a synthetic glucosederived advanced glycation end product that is immunologically cross-reactive with its naturally occurring counterparts. Bioconjugate Chem 11:39-45 